\title{
Treatments no longer in development for rheumatoid arthritis
}

\section{E Keystone}

\section{T CELLS AS THERAPEUTIC TARGETS}

Much of our experience with biological agents in autoimmune disease has been derived from studies of $\mathrm{T}$ cell directed therapy in rheumatoid arthritis (RA) (box 1). Data from these studies have provided substantial insight into study design, product development, and $\mathrm{T}$ cell biology. Initial studies entailed targeting of CD4 $\mathrm{T}$ cells with murine monoclonal antibodies (mAb) of differing isotypes directed at a variety of epitopes on the CD4 molecule. Between 1989-1994, eight short-term open label trials yielded promising results with clinical responses in 60\%-75\% of patients (reviewed in Strand and Keystone ${ }^{1}$ ). In 1996, seven years after the initial studies were published, the first randomised placebo controlled trial (RCT) of murine anti-CD4 mAb showing no clinical benefit was reported. ${ }^{2}$ A similar discrepancy in clinical outcome between early uncontrolled trials and placebo RCTs was also observed with a murine anti-CD5 immunotoxin conjugate, ${ }^{3}$ as well as the chimeric anti-CD4 mAb, cM412. ${ }^{4}$ This difference probably reflects both expectation bias on the part of the investigator and patient with "new and innovative therapy" as well as a placebo effect. In studies of anti-CD5 immunotoxin conjugate, for example a placebo rate as high 50\% was observed. A review of the problem by Epstein suggested that the results reflect more of an expectation bias than a placebo effect. ${ }^{6}$ His conclusion is based on an analysis of several trials involving chimeric anti-CD4 mAb in which the clinical benefit observed in the experimental group of the RCT was significantly lower than that observed in the open label groups. A placebo effect would be expected to yield comparable clinical responses between the two groups. The discrepancy between open label and RCT responses emphasises the magnitude of experimental bias in open label studies and as well as the need for vigorous blinding in RCTs. The data suggest that the use of a placebo group in early phase I/II studies would provide a reality check for our sometimes over enthusiastic response to these novel therapeutic approaches.

The effects of anti-CD4 mAb on CD $+\mathrm{T}$ cell survival have also provided insights into the pharmacodynamic approach to $\mathrm{T}$ cell directed therapeutic studies. Studies of murine anti-CD4 $\mathrm{Ab}$ revealed CD4 T cell depletion (hours to several months) irrespective of the antibody isotype while chimeric anti-CD4 ${ }^{7}$ and humanised anti-CDW52 (CAMPATH $1 \mathrm{H})^{8}$ caused prolonged peripheral blood $\mathrm{CD} 4+\mathrm{T}$ cell depletion out to five years. The dichotomy between clinical and biological effects of anti-CD4 treatment prompted pharmacodynamic studies of the synovial compartment. With chimeric $\alpha$-CD4 mAb, cMT412, a reduction in the number of inflammatory cells and adhesion molecules was seen in the tissues that failed to correlate with clinical improvement. ${ }^{9}$ There were no significant changes in the proportion of the synovial CD4+ cells or CD45 RO memory or CD45 RA+ naive cells after treatment. An insufficient decrease in synovial CD4 $+\mathrm{T}$ cells and persistence of cytokines IL1 $\beta$ and TNF $\alpha$ was cited to explain the discrepancy. Persistent synovial infiltration by CD4 $+\mathrm{T}$ cells was also observed during profound peripheral $\mathrm{T}$ cell depletion with CAMPATH-H treatment. ${ }^{10}$ More recent, pharmacodynamic
Biological agents no longer in development for RA $T$ cells as therapeutic targets

T cell depleting mAbs

- Anti-CD7

- Anti-CD5 immunoconjugate

- Murine and chimeric anti-CD4

- Primitised lgG, anti-CD4

- Campath-1H

T cell non-depleting agents

- DAB486/389 IL-2

- OKTcd4a mAb (lg64)

- Primitised lgG1 anti-CD4 mAb

studies demonstrated a correlation between the clinical response and percentage of anti-CD4 mAb (M412) coated CD4+ lymphocytes in the synovial fluid. ${ }^{11}$ The data suggest that the lack of clinical benefit with anti-CD4 treatment probably reflects inadequate dosing or duration of treatment, or both. These results also underscore the importance of the synovium as a window for monitoring particularly when no association between clinical and peripheral biological responses is apparent.

The lack of clinical efficacy with anti-T cell mAb may also reflect the relatively short duration of mAb treatment. In the systemic lupus erythematosus mouse model only prolonged treatment with anti-CD4 mAb to modulate $\mathrm{T}$ cell function could abrogate the development of the disease. ${ }^{12}$ Recent data demonstrating resistance of memory CD4+ T cells to anti-CD4 treatment may also explain the lack of clinical benefit of $\mathrm{mAb}$ treatment in RA. ${ }^{13}$ That this concept may be relevant is suggested by the increased numbers of circulating phenotypically active CD45 RO CD4 $+\mathrm{T}$ cells observed in RA patients after CAMPATH- $1 \mathrm{H}$ treatment. ${ }^{14}$ Finally, non-selective CD4+ T cell depletion may result in dysregulated immune function as CD4+ T cells subserve both helper and suppressor functions. This is supported by the finding of augmented rheumatoid factor production after anti-CD5 mAb treatment. ${ }^{15}$

The lack of clinical benefit with $\mathrm{T}$ cell depletion in RA is consistent with preclinical data in animal models of arthritis. In collagen induced arthritis profound depletion of CD4+ T cells with a heterologous anti-CD4 + mAb was insufficient to demonstrate a clinical effect. Indeed, studies showed that the Lyt- $1+\mathrm{T}$ cells remaining after anti-CD4 mAb were CD4 $+\mathrm{T}$ cells exhibiting low surface CD4 expression. Thus, only treatment that eliminated virtually all CD4 + T cells as well as ly $1+$ $\mathrm{T}$ cells was clinical benefit observed suggesting that an

Abbreviations: RA, rheumatoid arthritis; RCT, randomised controlled trial; MMP, matrix metalloproteinase 
extremely small number of CD4 + T cells are required to generate inflammation in CIA. Indeed, one recent report demonstrated the capability of a single CD4 $\mathrm{T}$ cell to generate a delayed hypersensitivity response. In contrast with collagen induced arthritis, anti-CD4 mAb have been demonstrated to be effective in adjuvant arthritis in rats. This discrepancy underscores the limitations of animal models in preclinical studies. More relevant preclinical data may be provided by an immunodeficient in vivo mouse model using human CD4/HLA DR4/TcR $\beta$ transgenic mouse.

The prolonged $\mathrm{T}$ cell depletion observed with chimeric/ humanised $\mathrm{mAb}$ is also consistent with previous murine data. Thus, studies in mice have demonstrated the correlation of aging with more prolonged regeneration of the lymphocyte pool after depletion. Short-term depletion of CD4+ T cells with heterologous anti-CD4 mAb was observed in relatively young mice comparable in age to mice used in the collagen induced arthritis model of RA. In contrast, long term depletion of CD4+ cells was observed in older mice of an age comparable to that of mAb treated patients. In vitro data from murine studies also support the concept of enhanced $\mathrm{T}$ cell depletion with chimeric anti-CD4 mAb since augmented T cell cytotoxicity, ADCC and apoptosis was observed with chimeric anti-CD4 mAb compared with the heterologous counterpart. Studies of such a chimeric mAb in animal models of RA may have been predictive of the observed long term depletion in humans with chimeric/humanised mAb. Taken together, these data emphasise the need for preclinical studies to more closely approximate the human therapeutic paradigm.

The clinical consequence of prolonged $\mathrm{T}$ cell depletion has been instructive. Despite prolonged CD4 depletion to levels comparable to those in AIDS patients, sepsis does not seem to be more prevalent. Whether the few lymphomas that occurred after CAMPATH- $1 \mathrm{H}$ treatment were a direct result of the treatment, requires long term follow up studies. Although septic complications of CD4+ cell depletion with anti-CD4 mAbs seem rare, concern exists regarding the use of new therapeutic agents in patients with persistent CD4+ T cell lymphopenia. Such patients may not have the opportunity to participate in future trials of immunomodulatory agents until their CD4+ T cells normalise.

A number of alternative approaches to T cell depletion in RA have been developed and seem promising. The clinical benefit observed in NZB mouse model with $\mathrm{F}(\mathrm{ab})^{2}$ anti-CD4 mAb suggests the utility of non-depleting anti-CD4 mAb in autoimmune disorders. ${ }^{16}$ In RA, preliminary results of open label trials with a primitised $\operatorname{IgG}^{17}$ and two humanised IgG4 ${ }^{18}{ }^{19}$ non-depleting anti-CD4 $\mathrm{mAb}$, suggest clinical benefit with only a transient reduction in CD4+ T cells. A RCT using the primitised $\mathrm{mAb}$ has confirmed these data. ${ }^{20} \mathrm{~A}$ second RCT was performed with primitised anti-CD4 mAb produced by a different manufacturing process resulted in reduced clinical efficacy and significant peripheral blood CD4+T-cell depletion. Both RCTs have been summarised recently.21 These data showed a dose dependent increase in peripheral blood CD4 T cell coating but a different pattern of CD4 depletion. Few patients in the first RCT had CD4 counts below $450 / \mathrm{mm}^{3}$ at the end of treatment while a substantial proportion of patients exhibited CD4 counts below this level in the second study. The $\mathrm{mAb}$ was produced by a different manufacturing process although both used similar Chinese hamster ovary cell lines. The most notable molecular difference between the anti-CD4 molecules was level of aggregate and non-glycosylated heavy chain. Comparisions in several in vitro and in vivo assays did not identify significant immunological differences. The clinical response was not correlated with CD4 depletion but was correlated with $\mathrm{CD} 4+\mathrm{T}$ cell coating with the nondepleting anti-CD4 mAb. Of significance, one humanised IgGl $\mathrm{mAb}$ (4162W94) resulted in substantial peripheral blood CD4 + T cell coating/modulation that correlated with clinical improvement. ${ }^{22}$ The mAb was well tolerated with no patients developing anti-idiotypic responses.

\section{TNF AS A TARGET}

An early approach to target TNF was the use of a recombinant fusion protein combining two extracellular domains of the human p55 kDa TNF receptor and one IgGl, heavy chain-R045-2081 (lenercept). A single dose IV study demonstrated clinical efficacy up to 28 days with a good safety profile. ${ }^{23}$ A three month study with monthly intravenous infusions also revealed efficacy associated with antibodies to lenercept in a proportion of patients..$^{24}$ No influence on efficacy or safety was noted. Intravenous infusions up to one year showed a 50\% drop out rate mainly for insufficient efficacy with a substantial clinical response in the completers. Serum antibodies were detected $60 \%$ of patients but demonstrated no influence efficacy or safety. A more modest effect was observed with lenercept produced by a different process. ${ }^{25}$ Studies of immunogenicity revealed anti-lenercept antibodies of $\operatorname{IgM}$ and IgG classes with the amount of IgG being dose dependent and amount of IgM correlating with rheumatoid factor. ${ }^{26}$ Anti-lenercept antibodies bound to the surface of human cells while inhibition studies revealed binding to Fc receptors rather than to TNFR55. No neutralising activity was detected. Lenercept given weekly by the subcutaneous route resulted in the generation of anti-lenercept antibodies that accelerated the clearance of lenercept with repeat dosing. ${ }^{27}$ There was no correlation between efficacy and lenercept or anti-lenercept antibodies. The development of lenercept was subsequently stopped. Clinical data remain unpublished.

\section{CYTOKINE ANTAGONISTS: IL4 AND IL10}

IL4 and IL10 defined initially as specific TH2 cytokines can suppress THI driven proinflammatory cytokines. IL10 is also produced by $\mathrm{B}$ cells, monocyte/macrophages and THl-like cells and thus cannot be considered a specific TH2 product. Both cytokines have the capacity to inhibit inflammation and joint destruction in RA and animal models of RA. ${ }^{28}$ IL10 is found in RA synovium and has been shown to have a suppressive role in RA joints. In contrast, IL4 production in RA synovium is low.

A phase I dose escalating DB-RCT safety study of recombinant human IL4 (rHulL4) was carried out in RA. ${ }^{29}$ Treatment with rhuIL4 did not produce significant clinical benefit in the short-term study but was well tolerated. Further development was halted.

rHuIL10 (given subcutaneously daily) was also evaluated in a DB-RCT phase I and cytokine response study in RA. During treatment a dose dependent thrombocytopenia was observed with a trend towards improvement in disease activity. Circulating levels of soluble TNFR (p55 and P75) as well as ILlra showed a significant increase at the highest doses with trends toward decreased ex vivo production of ILI $\beta$ and TNF $\alpha$ after PHA and LPS stimulation in rHuILlo treated subjects. rHuIL10 was well tolerated. Lack of benefit in subsequent studies resulted in discontinued development.

\section{MATRIX METALLOPROTEINASE INHIBITORS}

Matrix metalloproteinases (MMPs) including the collagenases, stromelysins and gelatinases and membrane-type MMPs play an important part in RA. ${ }^{31}$ As MMPs seem to play such a fundamental part in the pathophysiology of RA and because destruction they cause is largely irreversible, specific therapeutic strategies have been developed to inhibit their action. Synthetic inhibitors were initially developed for use in oncology to inhibit spread of cancer cells, as well as angiogenesis which promotes their growth. Several potent broad spectrum MMP inhibitors including batimastat (MB94), marinastat (BB 2516), and CG 270323A have been developed. Most have been used for oncology indications. The safety profile from phase II trials of marimastat demonstrated the most common drug related toxicity was musculoskeletal pain and stiffness initially involving peripheral small joints of the hands 
and spreading proximally in a time and dose dependent fashion. ${ }^{32}$ The side effect was reversible on drug withdrawal but the toxicity resulted in discontinuation of development.

BAY 12-9566-an oral broad spectrum inhibitor with activity against stromelysin and gelatinase-demonstrated efficacy in models of osteoarthritis. ${ }^{33}$ It was used in osteoarthritis trials but discontinued. R0113, 0830 inhibited several MMPs by oral administration including collagenase 2 and 3 and was shown effective in a menisectomy model of osteoarthritis. ${ }^{34}$ Clinical development was halted in phase II trials in osteoarthritis. The third promising oral MMP inhibitor developed for arthritis was Ro 32-3555 (Trocade)..$^{35}$ This hydroxamic acid was selective for collagenases 1,2 , and 3. It demonstrated efficacy in preserving cartilage in preclinical models of $\mathrm{P}$ acnes induced arthritis as well as models of osteoarthritis. Phase III clinical trials in RA were halted because of lack of efficacy at one year.

\section{SUMMARY}

Although a number of agents specifically developed for the treatment of RA have not continued in clinical development they have provided unique insights into study design, pharmacodynamics, immunobiology, and immunoactivity to biological agents.

\section{Author's affiliations}

E Keystone, The Centre for Advanced Therapeutics, Mount Sinai Hospital and University of Toronto, Canada

Correspondence to: Dr E Keystone, Mount Sinai Hospital, Room 1005, 600 University Avenue, Toronto, Ontario, Canada M5G 1X5; edkeystone@mtsinai.on.ca

\section{REFERENCES}

1 Strand V, Keystone EC. Biologic intervention in rheumatoid arthritis. Part I. Biotechnology in Health Care 1994; 1:283-302.

2 Wendling D, Racadot E, Widenes J and the French Investigators Group. Randomized double-blind, placebo-controlled multicentre trial of murine anti-CD4 monoclonal antibody therapy in rheumatoid arthritis. Arthritis Rheum 1996:39 (suppl):S245.

3 Olsen NJ, Brooks RH, Cush JJ, Lipsky PE, St Clair EW, Matteson EL, et al. A double-blind, placebo controlled study of anti-CD5 immunoconjuate in patients with rheumatoid arthritis. The Xoma Investigator Group. Arthritis Rheum 1996:39:1102-8.

4 Van der Lubbe PA, Dukmans BAC, Markusse WM, Nassander V Breedveld FC. A randomized double-blind placebo-controlled study of CD4 monoclonal antibody therapy in early rheumatoid arthritis. Arthritis Rheum 1995;38:1097-106

5 Moreland LW, Pratt PW, Mayes MD, Postlethwaite A, Weisman M, Schnitzer $T$, et al. Double-blind, placebo-controlled, multicentre trial using chimeric monocloncal anti-CD4 antibody cM-T412 in rheumatoid arthritis patients receiving concomitant methotrexate. Arthritis Rheum 1995;38:1581-8.

6 Epstein WV. Expectation bias in rheumatoid arthritis clinical trials. Arthritis Rheum 1996;39:1773-80.

7 Moreland LW, Bucy RP, Jackson B, Tracy J, Koopman WJ. Long-term (years) follow-up of rheumatoid arthritis patients treated with a depleting anti-CD4 monoclonal antibody cM-T412. Arthritis Rheum 1996;39 (suppl):S244.

8 Matteson EL, Yocum E, St Clair W, Achkar AA, Thakor MS, Jacobs MR, et al. Treatment of active refractory rheumatoid arthritis with humanized monoclonal antibody CAMPATH-1 $\mathrm{H}$ administered by daily subcutaneous injection. Arthritis Rheum 1995;38:1 187-93

9 Tak PP, van der Lubbe PA, Cauli A, Daka MR, Smeets TJM, Klein PM, et al. Reduction of synovial inflammation after anti-CD4 monoclonal antibody treatment in early rheumatoid arthritis. Arthritis Rheum 1995;38: 1457-65

10 Ruderman EM, Weinblatt ME, Thurmond LM, Pinkus GS, Gravallese EM. Synovial tissue response to treatment with CAMPATH-1H. Arthritis Rheum 1995;38:254-8.

11 Choy EHS, Pitzalis C, Cauli A, Bul JA, Schantz A, Woody J, et al. Percentage of anti-CD4 monoclonal antibody-coated lymphocytes in the rheumatoid joint is associated with clinical improvement. Arthritis Rheum 1996;39:52-6.
12 Connolly J, Roubinian JR, Wofsy D. Development of murine lupus in CD4-depleted NZB/NZW mice. Sustained inhibition of residual CD4+ T cells is required to suppress autoimmunity. J Immunol 1992;149:3083-8.

13 Goldschmidt TJ, Anderson M, Malmstrom V, Holmadahl R. Activated type II collagen reactive T cells are not eliminated by in vivo anti-CD4 treatment. Implications for therapeutic approaches on autoimmune arthritis. Immunobiology 1992; 184:359-71.

14 Jendio MC, Ganten T, Matteson E, Weyand CM, Goronzy JJ. Emergence of oligonclonal T cell populations following therapeutic $T$ cell depletion in rheumatoid arthritis. Arthritis Rheum 1995;38:1243-51.

15 Olsen NJ, Teal GP, Strand V. In vivo T cell depletion in rheumatoid arthritis is associated with increased in vitro $\lg M$-rheumatoid factor synthesis. Clin Immunol Immunopathol 1993;67:124-9.

16 Carteron NL, Schimenti CL, Wofsy D. Treatment of murine lupus with $\mathrm{F}(\mathrm{ab}) 2$ fragments of monoclonal antibody to L3T4. J Immunol 1989:142:1470-5.

17 Kane J, Solinger A, Yocum D, Lipani J, Tesser J, Wiesenhutter C, et al. Results of a multiple dose protocol 7002 using an immunomodulating, non-depleting primitized anti-CD4 monoclonal antibody in rheumatoid arthritis. Arthritis Rheum 1993;38 (suppl):S185.

18 Moreland LW, Bucy RP, Knowles RW, Wacholtz MC, Haverty TP, Koopman WJ. Treating rheumatoid arthritis with a non-depleting anti-CD4 monoclonal antibody. Arthritis Rheum 1995;38 (suppl):S186.

19 Panayi GS, Choy EHS, Connolly DA, Regan T, Manna VK, Rapson N, et al. Humanized non-depleting anti-CD4 monoclonal antibody treatment: suppression of disease activity and acute phase response. [Abstract]. Arthritis Rheum 1996;39:S244

20 Levy R, Weisman M, Weisnbutter C, Yocum D, Schnitzer T, Goldman A et al. Results of a placebo-controlled, multicenter trial using a primatized $\AA$ non-depleting, anti-CD4 monoclonal antibody in the treatment of rheumatoid arthritis. Arthritis Rheum 1996;39 (suppl):S122.

21 Mason U, Aldrich J, Breedveld F, Davis CB, Elliott $M$, Jackson $M$, et al. CD4 coating, but not CD4 depletion, is a predictor of efficacy with primitized ${ }^{T M}$ monoclonal anti-CD4 treatment of rheumatoid arthritis. J Rheumatol 2002;29:220-9.

22 Choy EHS, Connolly DJA, Regan T, Manna VK, Rapson N, Kingsley GH, et al. T cell hypothesis in rheumatoid arthritis tested by humanized non-depleting anti-CD4 monoclonal antibody treatment II: Clinical activity is related to pharmacodynamic effects. Arthritis Rheum 1996;39 (suppl):S244

23 Hasler F, van de Putte L, Dumont E, Kneer J, Bock J, Dickinson S, et al Safety and efficacy of TNF neutralization by lenercept in patients with rheumatoid arthritis exposed to a single dose. Arthritis Rheum 1996:39:S243.

24 Sander O, Rau R, van Riel P, van de Putte L, Hasler F, Baudin M, et al Neutralization of TNF by lenercept (TNFR 55, TgG1, Ro 45-2081) in patients with rheumatoid arthritis treated for 3 months. Results of a European Phase II trial. Arthritis Rheum 1996:39:S242.

25 Furst D, Weisman M, Paulus H, Bulpitt K, Weinblatt M, Polisson R, et al. Neutralization of TNF by lenercept (TNFR 55, TgGt, Ro45-2081) in patients with rheumatoid arthritis treated for 3 months: Results of a phase Il trial. Arthritis Rheum 1996;39:S243.

26 Christen V, Thuerkauf R, Stevens R. Immunogenicity of a human TNFR55-TgG1 fusion protein (lenercept) in rheumatoid arthritis (RA) and multiple sclerosis patients. Arthritis Rheum 1998;41:S58.

27 Kneer J, Luedin E, Lesslauer W, Lesslaver W, and the RA and MS study Groups. An assessment of the effect of anti-drug antibody formation on the pharmacokinetics and pharmcodynamics of sTNFr 55-lgG (S.C) in patients with rheumatoid arthritis. Arthritis Rheum 1998;41:S57.

28 Van Roon JAG, Lafeber FPJG, Bijlsma JWJ. Synergistic activity of interleukin-4 and Interleukin-10 in suppression of inflammation and joint destruction in rheumatoid arthritis. Arthritis Rheum 2001;44:3-12.

29 Van den Bosch F, Russell A, Keystone EC, Moreland LW, St Clair EW, Weinblatt $M$, et al. rHu IL-4 in subjects with active rheumatoid arthritis (RA): A phase I dose escalating safety study. Arthritis Rheum 1998;41:S56.

30 Maini RN, Paulus H, Breedveld FC, Moreland LW, St Clair WE, Russell $A S$, et al. rHu IL-10 in subjects with active rheumatoid arthritis (RA): $A$ phase I cytokine response study. Arthritis Rheum 1997;40:S224

31 Cawston T. Matrix metalloproteinases and TIMPs: properties and implications for the rheumatic diseases. Mol Med Today 1998;March.

32 Rasmussen HS, McCann PP. Matrix metalloproteinase inhibition as a novel anti-cancer strategy: a review with special focus on batimastal and marimastat. Pharmacol Ther 1997:25:69-75.

33 Chau T, Jolly G, Plym M, McHugh M, Bortolon E, Wakefield J, et al. Inhibition of articular cartilage degradation in dog and guinea-pig models of osteoarthritis by the stromelysis inhibitor BAY 12-9566. Arthritis Rheum 1998;41:S300.

34 Lollini L, Haller J, Eugni EM, Womble R, Martin R, Campbell J, et al. Disease modification by RS-130830 a collagenase-3 selective inhibitor in experimental osteoarthritis (OA). Arthritis Rheum 1997;40:S87.

35 Lewis EJ, Bishop J, Bottomley KM. Ro32-3555, an orally active collagenase inhibitor prevents cartilage breakdown in vitro and in vivo. Br J Pharmacol 1997;121:540-6. 